\title{
A new species of Giovanella Bonatto (Diptera, Calliphoridae, Mesembrinellinae) from Colombia
}

\author{
Marta Wolff ${ }^{1}$, Yardany Ramos-Pastrana² \& José Roberto Pujol-Luz ${ }^{3}$
}

\begin{abstract}
'Grupo de Entomología, Instituto de Biología, Universidad de Antioquia, A.A. 1226, Medellín, Colombia. mwolff@matematicas.udea.edu.co ${ }^{2}$ Grupo Fauna Silvestre, Museo de Historia Natural, Universidad de la Amazonia, Sede Centro, Carrera 11 No. 6-69 Barrio Juan XIII, Florencia, Caquetá, Colombia: bioyardany@yahoo.com.mx

${ }^{3}$ Departamento de Zoologia, Instituto de Ciências Biológicas, Universidade do Brasília, 70910-900 Brasilia-DF, Brasil. jrpujol@unb.br
\end{abstract}

\begin{abstract}
A new species of Giovanella Bonatto (Diptera, Calliphoridae, Mesembrinellinae) from Colombia. The Mesembrinellinae are exclusively Neotropical, with 33 nominal species distributed in nine genera. Only the genera Mesembrinella, Eumesembrinella, Huascaromusca and Laneella had until now been recorded in Colombia. In this work we present a new species of Giovanella Bonatto, 2005, genus with only one species, G. bolivar Bonatto, differing from the new species G. carvalhoi sp. nov., in the characters: legs entirely dark chestnut; thorax with dorsocentrals setae 1:2; abdomen with $\mathrm{T} 5$ with discal bristles poorly differentiated; T6 symmetric and paraphallus not extended and with denticules. Giovanella carvalhoi sp. nov. is from Cordillera Oriental, from the Departments of Caquetá (Amazonian foothills) and Santander, Colombia, collected between 2200-2400 m., and associated with decomposing organic matter. A key for the identification of males and females of the two species of Giovanella, illustrations of the genitalia and photographs of male and female of new species are also presented.
\end{abstract}

KEYWORDS. Andean biodiversity; Andean Region; Insecta.

Giovanella Bonatto, 2005 is one of the nine currently recognized genera of the Neotropical subfamily Mesembrinellinae Shannon, 1926, which includes 33 species distributed from southern Mexico to northern Argentina, 6 of which (in the genera Mesembrinella, Eumesembrinella, Huascaromusca and Laneella (Pape et al. 2004; Wolff et al. 2013) are recorded for Colombia. Giovanella was originally described based on the male holotype and a female paratype collected at 1000 masl in Bolívar (Venezuela) (Bonatto \& Marinoni 2005). A single species was known up to now, G. bolivar Bonatto, 2005. The shape of the anterior spiracle and the reduced number intra alar seta $(0: 1)$, support the monophyly of the genus (Bonatto \& Marinoni 2005).

Herein, Giovanella carvalhoi sp. nov., is described from Colombia, Departments of Caquetá (foothills of the Amazon) and Santander, Cordillera Oriental. A key for morphological identification of the two species of the genus Giovanella and illustrations of male genitalia and photographs of male and female of new species are also presented. This is the first record of this genus in Colombia and Andean region

\section{MATERIAL AND METHODS}

Type specimens were deposited at the "Laboratorio de Colecciones Entomológicas de la Universidad de Antioquia", Colombia (CEUA) and "Colección Entomológica del Museo de Historia Natural de la Universidad de la Amazonia”, Colombia (CUAM-E).

The holotype of Giovanella bolivar was not examined, and the identification of the new species was based solely in the original description of the type-species by Bonatto \& Marinoni
(2005). The morphological description used in the diagnosis and description of the new species follows McAlpine (1981). Abbreviations follow two sources, McAlpine (1981), and Bonatto \& Marinoni (2005). The measures 'head width' and 'frons width' follow Whitworth (2006), in which the frons width is taken from the narrowest point. Body length was recorded from the frons to the apex of the abdomen, and the wing length was taken from the alar sclerite to the wing apex. For the study of the male genitalia, the abdomen was detached from the thorax and submerged in $10 \%$ potassium hydroxide $(\mathrm{KOH})$ at room temperature during 24 hours, after it was rinsed in acetic acid for 10 minutes, and in distilled water for 10 minutes and finally placed in ethanol 70\% with glycerin (9:1), until dissection of the genitalia. For description and illustration purposes the genitalia was dissected using an Olympus SZ60 microscope; for the photographs of Figs. 1 and 2 we used a digital camera Leica DFC 500 coupled in a stereomicroscope Leica MZ16 and edited the captured images in the softwares IM50 (Leica) and Automontage (Syncroscopy); and for the photography of Fig. 3 we used a camera Cannon Powershot SX260IS. All the dissected structures were preserved in $200 \mu \mathrm{L}$ genitalia vials with glycerin; any remaining parts of the specimen were mounted on insect pins.

\section{Giovanella Bonatto}

Giovanella Bonatto, 2005: 884 (Type-species. Giovanella bolivar Bonatto, 2005: 884; Orig. des.).

The genus Giovanella had not been previously reported for Colombia. 
Diagnosis. According to Bonatto \& Marinoni (2005), this genus can be identified by the following combination of characters: anterior spiracle with buttonhole-like opening and no dorsal dilatation; acrostichal setae absent; intra-alar seta 0:1; hyaline wings with strongly developed maculae from base to $\mathrm{R}_{2+3}$; T5 with no discal setae. We consider that character T5 with no discal setae, should be amended, since in the examined specimens the T5 possesses discal setae (little differentiated), a condition which approaches Giovanella to Huscaromusca.

\section{Giovanella carvalhoi sp. nov.}

(Figs. 1-11)

Diagnosis. This species can be differentiated by the following combination of characters: medium sized; holoptic male; anterior spiracle with buttonhole opening, with no anterior dilatation; dorsocentral setae 1:2; discal scutellar seta absent; legs entirely black to dark chestnut; wings hyaline without strongly differentiated macula, with a grayish subtle patch from the base to $\mathrm{R}_{2+3} ; \mathrm{T}_{1+2}$ and $\mathrm{T} 3$ with a long single marginal lateral seta; T4 with entire line of marginal setae; $\mathrm{T} 5$ with discal bristles poorly differentiated and a complete line of thin marginals.

Male description. Head: Width $2.9 \mathrm{~mm}(\mathrm{n}=3)$, holoptic, frons narrow, its width at the narrowest point $0.04 \mathrm{~mm}(0.03-$ $0.05, \mathrm{n}=3$ ), dark chestnut coloration, strongly expanded at the lunule; parafrontalia with no setae, black colored with silvery tomentum; black parafacialia with silvery tomentum, third distal segment orange-yellow with scant setulae; dark gena with silvery tomentum, a row of setae with less diameter than vibrissae and with a few dark setulae; postgena with white tomentum and longer black and white hairs; pale face and clypeal membrane; orange palpus; ocellar triangle small and black, lunule, scape, and pedicel dark chesnut, dark flagellomere with gold tomentum; black occiput in the first third and in the transverse medial strip, with white tomentum and longer black and white hairs in the remaining parts. Chaetotaxy: two pairs of thin ocellar setae, parallel and proclinate, the posterior pair thinner and approximately $2 / 3$ the length of the anterior pair; two pairs of parallel and thin post-ocellar setae; external verticals absent; internal verticals crossed; one pair of thin and convergent paraverticals; postocular black, uneven in length, and homogeneously distributed until the gena; interfrontals and orbitals absent; facial carina slightly prominent, with two or three short and black bristles in the base above the vibrissa; vibrissa convergent; subvibrissal seta two thirds the length of the vibrissa.

Thorax: Black mesonotum, with white tomentum covering the entire thorax, creating well-defined stripes on the mesonotum and not well-defined on the metanotum; pleura, postpronotum, and mesonotum dark chestnut with some areas lighter; anterior spiracle yellow-orange with straight opening starting at the apical half with no distal widening (Fig 4); posterior spiracle dark chestnut with long setulae which are black on the lateroposterior and basal-half areas; legs entirely dark chestnut; mid femur with three apical posterodorsal setae and one anteromedial; posterior femur with three apical dorsal se- tae. Chaetotaxy: postpronotal setae (= humeral setae) 2; post postpronotal setae (= post humeral setae) 2 ; acrostichal setae $0: 0$; dorsocentral setae $1: 2$; intra-alar seta $0: 1$; supra-alar setae 3 first and last one of equal length, the central one approximately twice the length and thicker; presutural 1; post-supraalar setae 2, the anterior is thinner and half the length of the posterior one; discal scutellar seta 0 ; prebasal scutellar seta 1 very thin; basal scutellar seta 1; subapical scutellar seta absent; proepimeral setae 2; anepisternal setae 6; katepisternal setae $1+1$; merals as an inverted "L"; postalar wall with few setulae; suprasquamal ridge naked or with a single small seta.

Wings: Hyaline with a mild smoked alar macula starting at the base, restricted to bc, c, sc, and $\mathrm{rl}$ cells, the remaining wing only infuscated around veins; tegula and basicosta dark chestnut with some small areas lighter; subcostal sclerite and stem vein naked; meeting point of $\mathrm{R} 2+3$ and $\mathrm{R} 4+5$ with tree reduced setulae. Distance between apex of $\mathrm{M}$ and $\mathrm{R} 4+5$ much less than half the length between apex of R $2+3$ and $R 4+5$. Upper calypter hyaline, with dark edge; lower calypter naked, dark on its apical half, with lobular internal margin, not directed towards the scutellum.

Abdomen: Segments $1+2$ with yellow coloration dorsally and ventrally; segment 3 yellow until the posterior ventral margin, and until the medial region in dorsal view, with dark chestnut central-lateral macula that expands towards the lateral regions; $\mathrm{T} 1+2$ with a group of poorly differentiated lateral discal bristles that do not extend beyond the marginal bristle; T $1+2$ and 3 with a long marginal lateral bristle; T4 with a entire line of long marginal bristles; T5 with discal bristles poorly differentiated and a complete line of thin marginals; sternite 5 as the fig (Fig 5).

Terminalia: T6 symmetrical, partially connected to $\mathrm{T} 7+8$ (Fig 6); apical limb of paraphallus not extended and with denticules arranged on a no lineal fashion (Figs 7, 8); pregonite and posgonite characteristic (Fig 9); surstyli and cerci arcuate (Figs 10, 11).

Measurements: Body length $10 \mathrm{~mm}(\mathrm{n}=3)$.

Female description. Differs from male in the following characters: Head: Width 3.20mm (3.0-3.30, $\mathrm{n}=9)$, dichoptic, frons width at the narrowest point $0.75 \mathrm{~mm}(0.70-0.80, \mathrm{n}=9)$, long, with a small basal portion near the lunule reddish chestnut and remaining areas black colored. Chaetotaxy: a pair of crossed interfrontal bristles; frontals thin and short, vestigial upper orbitals; internal verticals, ocellar, post-ocellar and paraverticals as in the male. Thorax and abdomen: As in the male. Terminalia: Normal epiproct; $\mathrm{T} 7$ continuous, $\mathrm{T} 8$ continuous and located dorsally with two bristles on the internal edge.

Measurements: Body length $10 \mathrm{~mm}(\mathrm{n}=9)$.

Comments. The specimens were collected with Van Someren-Rydon traps baited with decomposed fish, which might relate this species with carrion. A single species has been described for the genus, G. bolivar. This paper presents characters that clearly allow differentiation of the new species.

Etymology. In honor to Dr. Claudio José Barros de Carvalho, for his invaluable contribution to the study of the dipterofauna of Colombia and the training of researchers in this group. 

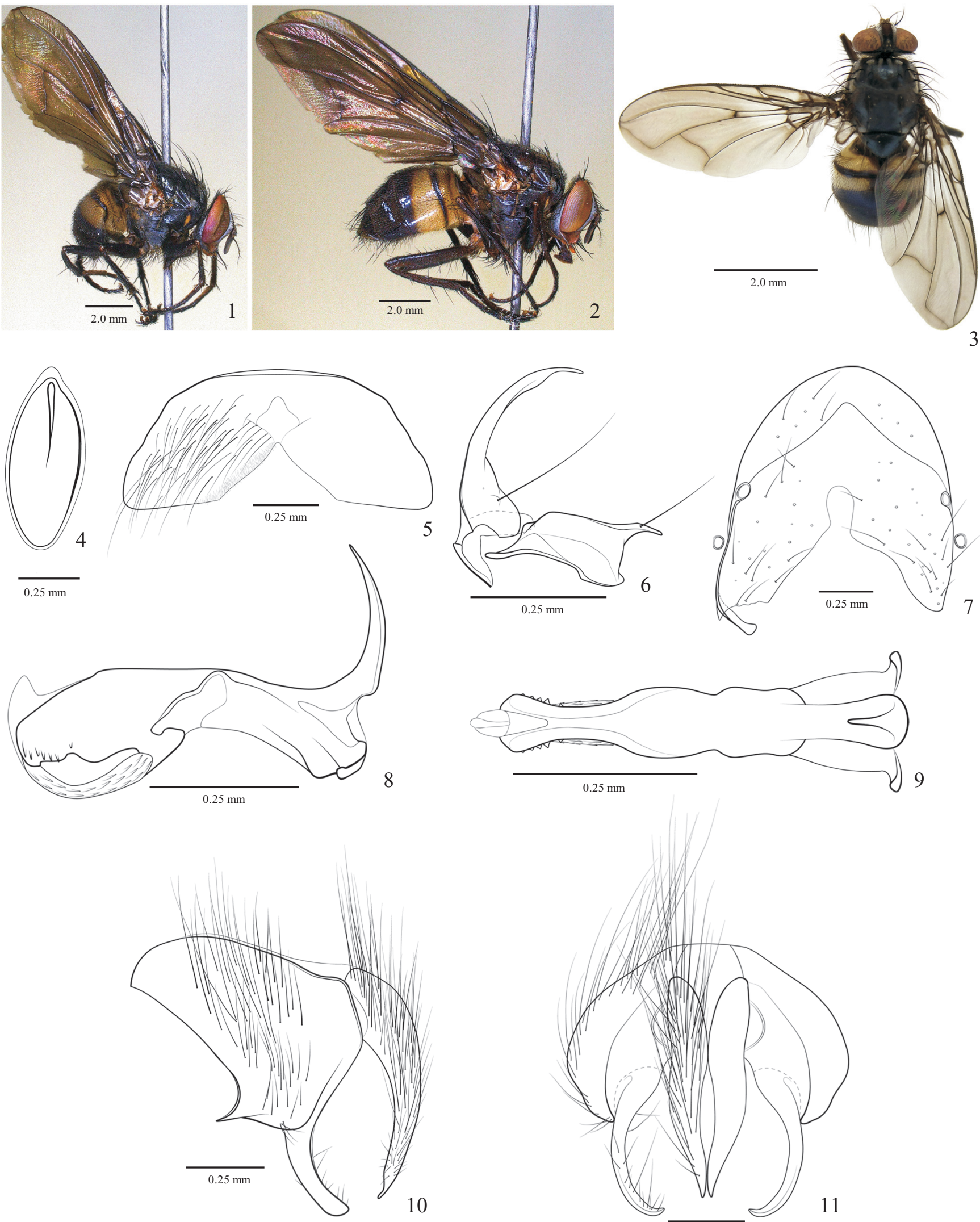

0

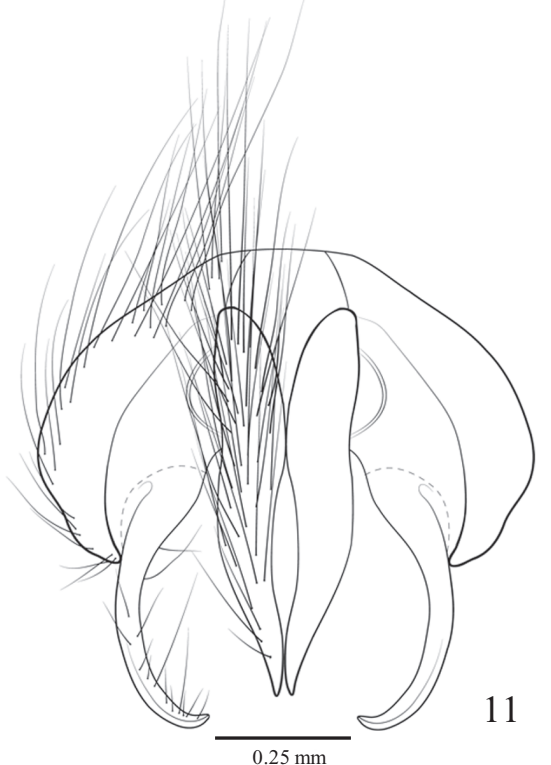

Figs. 1-11. Giovanella carvalhoi sp. nov. 1. Male, habitus in lateral view. 2. Female, habitus in lateral view. 3. Female, habitus in dorsal view. 4-11. Male terminalia. 4. Anterior spiracle. 5. Abdominal sternite 5, ventral view. 6. Abdominal tergite 6 and 7+8, dorsal view. 7. Aedeagus, dorsal view. 8 . Aedeagus, lateral view. 9. Posgonite and pregonite, right lateral view. 10. Epandrium, surstylus and cercus, lateral view. 11. Epandrium, surstylus and cercus, posterior view. 
Type material. Holotype male: "CO [Colombia] Caqueta/Florencia, N0145 36", W7546غ̇24". 2210m [meters] asl/T. vsr fish/03 June, 2011. Y. Ramos. CEUA [red label]. Paratypes: "CO [Colombia] Caqueta/ Florencia,/Km 49/2210m [meters] asl/T. vsr fish/24 November, 2011. Y. Ramos. CEUA, one male and two females [green label].

Additional examined material. "COLOMBIA: Caquetá/vía FlorenciaSuaza/"El Pórtico", 49Km, N0145'36", W7546'24". Bosque 2210-2400 m., Van Sommeren-Rydon trap baited with fish, 10.vi.2011, coll. Y. Ramos, 3 males and 4 females; Santander/Piedecuesta, N07 $05^{\prime}$, W73 $01^{\circ}$. Bosque 2200-2400 m., Van Sommeren-Rydon trap baited with fish, 25.viii.2001, colls. P. Duque \& A. Vélez, 5 females.

Distribution. Colombia: Caquetá Department, foothills of the Colombian Amazon and Santander Department of Cordillera Oriental (Andean system).

\section{Key to the species of genus Giovanella}

1. Legs with orange femurs, apical 1/4 chestnut; anterior and posterior spiracles yellow-orange, T6 asymmetrical; paraphalus without denticules

Giovanella bolivar Bonatto, 2005

1'. Legs entirely dark chestnut; anterior spiracle yellow and posterior spiracle dark chestnut; T6 symmetrical; paraphalus with denticules Giovanella carvalhoi sp. nov.

\section{ACKNOWLEDGMENTS}

Thanks to the entomology seed research of the University of the Amazonia. Biologist Carolina Rivera Alvarez pro- duced the illustrations. To Colciencias Project 601-2009 (YRP). To Conselho Nacional de Desenvolvimento Científico e Tecnológico/CNPq and Fundação de Apoio à Pesquisa do Distrito Federal/FAP-DF for the grants (JRPL and MW). To Estrategia de Sostenibilidad 2013-2014 de la Universidad de Antioquia for the grants (MW). To Taxonline, Rede Paranaense de Coleções Biológicas, UFPR for taking photographs of the male holotype and one female paratype. To Andres Vélez for taking photograph of dorsal view of the female. To Dr. Nelson Papavero for comments and suggestions on this manuscript and to anonymous reviewers for useful comments which helped to improve it.

\section{REFERENCES}

Bonatto, S.R. \& Marinoni, L. 2005. Gêneros e espécies novos de Mesembrinellinae (Diptera, Calliphoridae) da Costa Rica e Venezuela. Revista Brasileira de Zoologia 22: 883-890.

McAlpine, J.F. 1981. Morphology and terminology - Adults, p. 9-63. In: McAlpine, J.F. (ed.). Manual of Nearctic Diptera. Vol. 1, Ottawa, Research Branch Agriculture Canada, Monograph 27.

Pape, T., Wolff, M. \& Amat, E. 2004. Los Califoridos, Estridos, Rinoforidos y Sarcophagidos de Colombia (Diptera: Calliphoridae, Oestridae, Rhinophoridae, Sarcophagidae). Revista Biota Colombiana 5: 201-208.

Whitworth, T. 2006. Keys to the genera and species of blow flies (Diptera: Calliphoridae) of America North of Mexico. Proceedings of the Entomological Society of Washington 108: 689-725.

Wolff, M., Ramos-Pastrana, Y. \& Pujol-Luz, J.R. 2013. Description of the male of Laneella perisi (Mariluis) (Diptera: Calliphoridae) n. comb. Neotropical Entomology 42: 58-62. 